\title{
The Effect of Media Representations and Stigma on Public Perception of Mental Disorders from Late 20th to Early 21st Century

\author{
Xintong Chen
}

\author{
York School, Monterey, CA, 93940, United States \\ Corresponding author's email: 2698307889@qq.com
}

\begin{abstract}
The late 20 th and early 21 st century was featured by the rapid growth of media and means of communication, and discussions on the effect media have on social stereotypes have attracted new academic attention. One of the existing stigmas being intensified by the media representation is the mental health stigma, from which patients with a history of mental disorders are often misunderstood by the society, and thus be socially isolated and personally discriminated against To understand how media contribute to the stigmatization process, the author came to the following conclusions through examing media's representation of the mentally ill: first, newspaper articles and entertainment media often inaccurately attribute violence to mental disorders, while the fact is that only a small portion of violence is committed by the mentally ill. Secondly, the media draw causal relationships between terrorism and mental illnesses, especially when 9/11 and mass shootings became the center of public attention, although mental disorders alone are not sufficient predictors of terrorist activities. Lastly, medical terms appearing in newspapers and social media are frequently used in non-medical contexts that have a negative indication, resulting in stigmatization. All three factors reflect the role the media play contributing to mental health stigma. Researching about these three factors contributing to mental health stigma lays the foundation for future anti-stigma actions to take place. Further research may include effective ways to eliminate mental health stigma, allowing researchers to design solutions to counteract misunderstandings and to build successful communication.
\end{abstract}

Keywords: Mental health stigma, Anti-stigma, Media representation, Misinformation

\section{INTRODUCTION}

In the past few years, more and more attention has been paid to mental health-related issues, and common disorders such as depression and anxieties are frequently discussed. Yet there is not enough focus on the mental health stigma, as it also causes great personal stress to the patients. This paper digs deeper into the topic to discover the source of mental health stigma, and thus explores better ways of diminishing it. Per the research, a significant relationship between mental health stigma and media is found. Because the media were failing in delivering accurate, unbiased information, stigmatization occurred as a result. To solve the problem that stemmed from miscommunication, one must correct the preexisting stereotypes toward the mentally ill through more precise and scientific clarification.
This research was started by searching for the keywords on relatively authoritative sites such as GoogleScholar and Jstor. Several literary reviews provided informative descriptions of the issue and guided the author to some primary sources or important studies down on the topic. Then those studies are more closely analyzed, summarized and organized into the author's own opinion in the paper form. Finally, based on the information gathered, a potential solution is suggested for the mental health stigma, backed up with reasons for its practicality.

\section{ADVERSE EFFECTS OF MENTAL HEALTH STIGMA}

The mental health stigma is reported directly causing mental distress for individuals under it. Experiences may include shame, blame on oneself, secrecy, a "black sheep of the family" role, isolation, and social exclusion [1]. 
Moreover, the stigma influences their economic and educational opportunities. Research has shown that the mentally ill, due to the labeling effect, are generally at higher risks of being rejected by employers or school admissions. Therefore, the stereotypes and discriminations of the mental patients can directly lead to an inferior position in the job market or educational institute, causing them to internalize negative responses from the outside, withdraw from social and occupational functioning, and devalue themselves [2].

\section{MEDIA'S ROLE IN THE STIGMATIZATION OF MENTAL DISEASE}

The media had contributed to the stigmatization of mental illnesses due to its dominant role shaping public conceptions. Since the late 20th century with a boom of means of communication, a diversity of media has become the main source of information for many people. In the field of clinical psychology, mass media are the most common sources of information that the general public has access to, as a 1990 survey demonstrated. It had a sample size of 1300 subjects, and among them, 74\% indicated that newspapers are where they acquire most of their understanding of psychological disorders [3]. It is important to recognize the dominant effect media have on public conceptions on a specific topic, especially for one like psychiatry that only a small percentage of the population possess an academic background. To summarize, because of the significant role of media in influencing public opinions, misinformation and improper deliveries are likely to cause stigmatization.

\section{WAYS MEDIA CONTRIBUTE TO MENTAL HEALTH STIGMA}

It is clear that mental health patients are often portrayed negatively. In a study in 1997, the consistency of stereotypical portrayals of mental illnesses in the media was analyzed. The result demonstrated that a negative attitude toward diagnosed children had lasted for a decade, and for adults more than 22 years, despite some interventions in between [4]. Such consistent information received by the public will inevitably lead to stigmatization as media play a crucial role in the formation of stereotypes.

\subsection{Relation to Violence}

One of the features of mental illnesses presented by mass media is a connection to violence, as an ill effect of miscommunication. In 2002, one research conducted by Wahl, Wood, and Richards examined the most common theme associated with mental disorders in newspaper articles. Using a computer database, 1999 stories from 6 different newspapers containing the key term "mental illnesses" were randomly selected, and $26 \%$ of articles attributed the violence to psychological disorders. Moreover, the researchers also discovered that those articles tend to relate violence and mental illnesses in their headlines. For example, "History of Schizophrenia Detailed for Man Held in Subway Attack" is one of the titles Wahl cited from the New York Times [3]. Having established that the media has a significant role in influencing public perception, it is fair to claim that such news headlines are likely to result in people's misunderstanding toward the mentally ill.

A New York Times article [5] illustrated how news media were drawing a direct causal relationship between mental illnesses and violence. The author started the article by introducing the case of a man named Michael Vernon, who committed a murder in a Bronx shoe store and was diagnosed as having paranoid schizophrenia. In the rest of the article, he argues that the mentally ill should not be given freedom to live independently without being monitored to take medications, because he assumes that most mental patients "may deteriorate and wind up in the street or the hospital or jail" once they are off from their medication and "not realize they are ill" [5]. $\mathrm{He}$ is failing to deliver the fact that a large portion of the mentally ill are non-violent. Such an indication of the idea that "because one person with severe mental illness is violent, all mentally ill are violent" is erroneous and misleading.

In addition to news articles, entertainment media is another source of misinformation on mental illnesses. One 1996 research focused specifically on the movie productions of Walt Disney. Through qualitative observations, researchers traced the references to "madness" in numerous Disney films across a wide period such as Alice in Wonderland in 1951, Mary Poppins in 1964, and Beauty and the Beast in 1992. The majority of the characters regarded as "mad" are depicted as unattractive or with violent tendencies [7]. Since the main audiences of Disney films are children still in a process of forming personal values, it is likely that constant reinforcement of the idea "all 'mad' people are violent and bad" will result in stereotyping.

\subsection{Relation to Criminal Activities and Terrorism}

In addition to the association with violence, mental illnesses are also associated with criminal activities and terrorism, regarding it as an important cause [8]. Emma E. McGinty, in her study about the media coverage of gun violence in the U.S. from 1997 to 2012, has revealed that several mass shooting cases receiving extensive media coverage were executed by people with serious mental illnesses, such as the Virginia Tech, Tucson, and Aurora shooters. She also noticed that in those media reports, "dangerous people" are more frequently considered as the cause of mass shootings than "dangerous weapons" [9] However, McGinty's research suggests that media 
tended to exaggerate the participation of the mentally ill in mass shootings, as the majority of psychiatric patients are not violent, not to mention being involved in criminal activities or terrorism [10]. Furthermore, according to [11] and [12], mental illnesses do not result directly in criminal activities or terrorism. However, this is what the media do not usually mention.

\subsection{Misuse of Medical Terms}

The media frequently use psychological terms improperly, resulting in misunderstandings, which also contributed to the stigmatization of mental illnesses. In [13], researchers analyzed the metaphorical uses of the word "schizophrenia" and comparing the number of metaphorical uses between the word "cancer" and "schizophrenia", as the word "cancer" was well known for being stigmatized in media expressions. 1740 newspaper articles mentioning the word "schizophrenia" or "cancer" from 1996 to 1997 were selected and viewed. The results turned out that only $1 \%$ of articles mentioning cancer use the illness as a metaphor, while $28 \%$ of articles containing "schizophrenia" used it in metaphorical ways [13]. Among the metaphors of the word "schizophrenia", the majority of the descriptions have a negative indication. For example, Duckworth et al. cited from Los Angeles Times an article titled "The Nation' s Schizophrenic Perspective on Drug ", from The Washington Post cited "the Schizophrenia of a Public that Wants less Government Spending, more Government Services, and Lower Taxes", and from Chicago Tribune cited "the Schizophrenic Actions of the Patriots" [13]. All these titles had distorted the original meaning of the word "schizophrenia", making it a symbol of irrationality and absurdity, although the actual medical definition is simply to have abnormal perceptions of reality. People's misinterpretations of the word " schizophrenia " demonstrated how improper phrasings, a typical error of communication, can lead to stigmatization [13].

Meanwhile, the indisputable importance of social media in shaping public belief magnifies misinformation, thus reinforces mental stigma with its popularity. One recent research had collected 1,059,258 tweets about mental and physical health, and 1300 were selected for analysis. The conclusion was that posts related to mental health are more likely to be stigmatized compared to ones about physical health [14].

\section{MEDIA AS A SOLUTION TO THE STIGMA}

Although it is proven that inaccurate media representation of mental illnesses gives a push to stigmatization of psychological disorders, one should not ignore the fact that media can also reduce stigma if utilized properly.
Several past attempts are facilitated by the media. In the 1990s, there were heated discussions about the rights and stereotypes of individuals with mental disorders. Carried out by the Royal College of Psychiatrists, a 5year British anti-stigma campaign named "Changing Mind: Every Family in the Land" attempted to educate the public about the misinformation of serious mental health illnesses [15]. However, it had minor impacts on the public conceptions [16]. Similarly, the U.S. Equal Employment Opportunity Commission (EEOC) also prohibited discrimination against people with a history of mental health disabilities, yet stereotypes related to mental illnesses still exist [3]. If one examines influential contemporary anti-discrimination movements, such as Me Too movement and Black Lives Matter Movement, one thing shared in common among them is large volumes of personal stories shared by real people. Those are great examples to learn from as they successfully changed public opinions on related issues. Based on these facts, one possible reason for the limited influence of the past attempts is the lack of participation of actual patients with mental disorders.

Moreover, the internet will still be an ideal platform, for it is a widely used and some online websites create a relatively safe and free environment for people with serious mental illnesses, an especially stigmatized group, to share their personal experiences [17]. In fact, one Australian-based service site named Reach Out has already proven to be effective in reducing mental health stigma [18]. Thus, it is likely that a multifunctional online mental health service site will also work in the U.S. to reduce stigma by scientifically based communication and participation of the stigmatized group sharing their personal experiences. However, no matter what approach will be taken in the future to achieve understanding of the public toward the mentally ill, it is always important to pay attention to the communication of mental-healthrelated information. Mistakes such as unscientifically associating mental illness with violence and criminal activities or misusing psychological terms must be avoided in public media for stigma prevention.

\section{CONCLUSION}

The area of mental health stigma is worthwhile for further explorations as it ties closely to social experiences of the mentally ill. Not only the media, other aspects such as education, daily conversations, artistic productions, etc. might also have contributed to the stigmatization process. Future research can potentially focus on how different factors influence each other, and thus to devise plans to reduce mental health stigma. Another action that can be carried out to benefit the mentally ill under discriminations is to actively help them to develop selfesteem and teach them coping mechanisms. Since mental health stigma is a long-lasting civic issue, guiding its victims to avoid being affected on personal levels is 
equally important as reducing stigma. The writer encourages that while searching for solutions for mental health stigma, efforts can also be made to help patients with high risk of being discriminated against, such as people with schizophrenia and bipolar disorder, to be informed of misconceptions the public might have for them. With proper help from the professionals, patients with mental disorders might be able to identify misleading or false information exposed to them and be less impacted by the stigma.

\section{REFERENCES}

[1] Byrne, Peter."Stigma of Mental Illness and Ways of Diminishing it". Advances in Psychiatric Treatment, 6(1), 65-72 (2000). doi:10.1192/apt.6.1.65

[2] Link, B.G. "Understanding Labeling Effects in the Area of Mental Disorders: An Assessment of the Effects of Expectations of Rejection". American Sociological Review, 52 (1987), 96 - 112

[3] Wahl, Otto F. "News Media Portrayal of Mental Illness." American Behavioral Scientist, vol. 46, no. 12, 2003, pp. 1594-1600., doi:10.1177/0002764203254615.

[4] Byrne, Peter. "Psychiatric Stigma: Past, Passing and to Come." Journal of the Royal Society of Medicine, 90.11, 1997: 618-621.

[5] Issac, Rael Jean, and D. J. Jaffe. "Mental Illness, Public Safety." The New York Times 23 Dec. 1995. Print.

[6] Kifner, John. "Shooting in Brooklyn: A Special Report.; Police Account Challenged In Killing of Troubled Man." The New York Times 4th Oct. 1999. Print.

[7] Beveridge, A. "Images of Madness in the Films of Walt Disney”. Psychiatric Bulletin, 20, 1996, 618 620 .

[8] Schildkraut, Jaclyn, and Glenn W. Muschert. "Violent Media, Guns, and Mental Illness: The Three Ring Circus of Causal Factors for School Massacres, as Related in Media Discourse." Fast Capitalism 10.1 (2013).

[9] Mcginty, Emma E., et al. "News Media Framing of Serious Mental Illness and Gun Violence in the United States, 1997-2012." American Journal of Public Health, vol. 104, no. 3, 2014, pp. 406-413., doi:10.2105/ajph.2013.301557.

[10] Mcginty, Emma E., et al. "Trends In News Media Coverage Of Mental Illness In The United States: 1995-2014." Health Affairs, vol. 35, no. 6, 2016, pp. 1121-1129., doi:10.1377/hlthaff.2016.0011.
[11]. Gill, Paul, and Emily Corner. "There and Back Again: The Study of Mental Disorder and Terrorist Involvement." American Psychologist 72.3 (2017): 231-41. Print.

[12] Weatherston, David, and Jonathan Moran. "Terrorism and Mental Illness: Is There a Relationship?." International Journal of Offender Therapy and Comparative Criminology 47.6 (2003): 698-713

[13] Duckworth, Kenneth, et al. "Use of Schizophrenia as a Metaphor in U.S. Newspapers." Psychiatric Services, 1 Oct. 2003.

[14] Robinson, Patrick, et al. "Measuring Attitudes Towards Mental Health Using Social Media: Investigating Stigma and Trivialization." Social Psychiatry and Psychiatric Epidemiology 54.1 (2019): 51-58.

[15] Luty, Jason, et al. "Effectiveness of Changing Minds Campaign Factsheets in Reducing Stigmatized Attitudes Towards Mental Illness." Psychiatric Bulletin 31.10 (2007): 377-381.

[16] Harper S. "Media, Madness and Misrepresentation: Critical Reflections on Anti-Stigma Discourse". European Journal of Communication. 2005;20(4):460-483. doi:10.1177/0267323105058252

[17] Naslund, John A., et al. "Naturally Occurring Peer Support through Social Media: The Experiences of Individuals with Severe Mental Illness Using YouTube.” PLOS ONE, Public Library of Science, journals.plos.org/plosone/article?id=10.1371\%2Fjo urnal.pone.0110171.

[18] Burns, Jane M., Lauren A. Durkin, and Jonathan Nicholas. "Mental Health of Young People in the United States: What Role Can the Internet Play in Reducing Stigma and Promoting Help Seeking?." Journal of Adolescent Health 45.1 (2009): 95-97. 